УДК 615.322:582.883.4

\title{
КОЛИЧЕСТВЕННОЕ ОПРЕДЕЛЕНИЕ ТЕРПЕНОИДНЫХ ФЕНОЛАЛЬДЕГИДОВ В ЛИСТЬЯХ ЭВКАЛИПТА ПРУТОВИДНОГО
}

\author{
() Р.ШІ. Хазиев", М.В. Васильева, А.С. Макарова, Л.Т. Мусина
}

Казанский государственный медицинский университет, ул. Бутлерова, 49, Казань, 420012 (Россия), e-mail: xaziev@inbox.ru

Разработан способ определения терпеноидных фенолальдегидов в листьях эвкалипта прутовидного (Eucalyptus viminalis Labill.) с спектрофотометрическим методом. Относительная ошибка определения не превышает $\pm 2,41 \%$. Показана связь между уровнем терпеноидных фенолальдегидов, определяемых разработанным методом, и антибактериальной активностью содержащих их извлечений.

Ключевые слова: эвкалипт прутовидный, Eucalyptus viminalis Labill., терпеноидные фенолальдегиды, стандартизация, антибактериальная активность.

\section{Введение}

Листья эвкалипта прутовидного, служащие источником ряда препаратов антимикробного и противовоспалительного действия - настойки, эфирного масла, «Хлорофиллипта», «Галенофиллипта», стандартизуются в настоящее время Государственной фармакопеей по содержанию эфирного масла [1, с. 257-258]. Вышедшие в последние годы нормативные документы различных производителей (ОАО «Красногорсклексредства», ОАО «Фармацевтическая фабрика Санкт-Петербурга», ООО ПКФ «Фитофарм»), кроме этого показателя стандартизуют листья эвкалипта прутовидного и по содержанию терпеноидных фенолальдегидов [2-4]. При небольших различиях метод определения терпеноидных фенолальдегидов в этих нормативных документах принципиально один и тот же - фенолальдегиды экстрагируются 70 или 95\% спиртом и полученный раствор фотометрируется при 278 нм. Однако, на наш взгляд, этот метод дает завышенные результаты, поскольку спиртовое извлечение не подвергается никакой очистке и будет содержать помимо фенолальдегидов, другие фенолы, находящиеся в листьях эвкалипта (флавоноиды, танины, фенолкарбоновые кислоты) и поглощающих свет при используемой длине волны.

Целью нашей работы - разработка метода количественного определения фенолальдегидов лишенного этого недостатка.

\section{Экспериментальная часть}

В качестве объекта исследования использовали листья эвкалипта прутовидного (Eucalyptus viminalis Labill.) из семейства миртовых - Myrtaceae, заготовленные в сентябре 2011 г. в Абхазии.

Хазиев Рамиль Шамилевич - кандидат биологических наук, доцент кафедры фармакологии, тел.: (843) 521-27-88, e-mail: xaziev@inbox.ru Васильева Марина Вячеславовна - студентка, тел.: (843) 521-27-88

Макарова Алёна Сергеевна - студентка, тел.: (843) 521-27-88, e-mail: anela_90@mail.ru Мусина Линара Табрисовна -профессор кафедры микробиологии, доктор медицинских наук, тел.: (843) 236-13-51, e-mail: musina@kgmu.kcn.ru
Запись УФ-спектров и определение оптических плотностей полученных растворов проводили на спектрофотометре LAMBDA 25 (Perkin Elmer, США) в кювете с толщиной слоя 10 мм.

Для тонкослойной хроматографии использовали пластины «Сорбфил» («ПТСХ-АФ-В», производитель ЗАО «Сорбполимер»). Извлечения хроматографировали в системе этилацетат - уксусная кисло-

\footnotetext{
* Автор, с которым следует вести переписку.
} 
та - вода $(5: 1: 1)$, детектирование зон абсорбции флавоноидов проводили в видимом и УФ-свете до и после обработки $3 \%$ спиртовым раствором алюминия хлорида, дубильных веществ и фенолкарбоновых кислот - до и после обработки хлоридом (III) железа.

Оценку антибактериальной активности проводили методом двукратных серийных разведений на мясо-пептонном бульоне (МПБ) при рН 7,0 с тест-микробом Staphylococcus aureus ATCC 6538-Р [5]. Однако метод серийных разведений в МПБ зачастую не позволяет визуально определить наличие или отсутствие роста из-за помутнения среды.

Чтобы устранить этот недостаток фармакопейной методики, нами был разработан метод, где антибактериальную активность определяли, делая пересев из каждой пробирки на чашки с мясо-пептонным агаром (МПА), которые затем инкубировали в термостате в течение 18-24 ч. Отмечали рост микроорганизмов. Разведение препарата, на котором отсутствовал рост тест-штамма, характеризовало антибактериальную активность препарата.

\section{Результаты и обсуждение}

Проведенное нами определение содержание терпеноидных фенолальдегидов в образцах листьев эвкалипта прутовидного методами, изложенными в нормативных документах различных производителей [2-4], дало результаты на уровне от 11 до 15\% при норме 3\% [3, 4] и 5\% [2], что косвенно свидетельствовало о правомерности наших сомнений в точности данных методик. К тому же УФ-спектр полученного спиртового экстракта имел в измеряемом диапазоне скорее точку перегиба, нежели четко выраженный максимум, что также говорило о поглощении сопутствующих веществ (рис. 1).

Терпеноидные фенольдегиды (эуглобали, макрокарпали и сидероксилонали) являются липофильными соединениями и, по мнению ряда авторов, лучше всего экстрагируются не этиловым спиртом, а петролейным эфиром с небольшими добавками (до 20\%) ацетона [6]. Поскольку сопутствующие вещества фенольной природы, искажающие результаты определения фенолальдегидов, о которых речь шла выше, имеют гидрофильную природу, мы использовали избирательную экстракцию фенолальдегидов гидрофобным растворителем - гексаном. ТCX-анализ показал отсутствие вышеупомянутых примесей в гексановом извлечении. УФ-спектр гексанового экстракта имел отчетливый максимум при $278 \pm 3$ нм, характерный для фенолальдегидов эвкалипта, который и был выбран в качестве аналитической длины волны (рис. 2).

Известно, что фенольные гидроксилы, находящие по соседству с карбонильной группой, могут образовывать комплексы с хлоридом алюминия, которые вызывают батохромный сдвиг максимумов поглощения в УФ-спектре. В частности, эта реакция широко используется в анализе флавоноидов [7]. Мы предположили, что фенолальдегиды эвкалипта могут образовывать аналогичные комплексы с хлоридом алюминия с соответствующим батохромным сдвигом.

Для проведения реакции гексановое извлечение упаривали под вакуумом, остаток растворяли в 95\% этиловом спирте и добавляли $3 \%$ спиртовый раствор алюминия хлорида. Наблюдаемый батохромный сдвиг максимума поглощения (около 15-20 нм) явился дополнительным доказательством того, что поглощение гексанового экстракта в УФ-свете обусловлено терпеноидными фенолальдегидами эвкалипта.

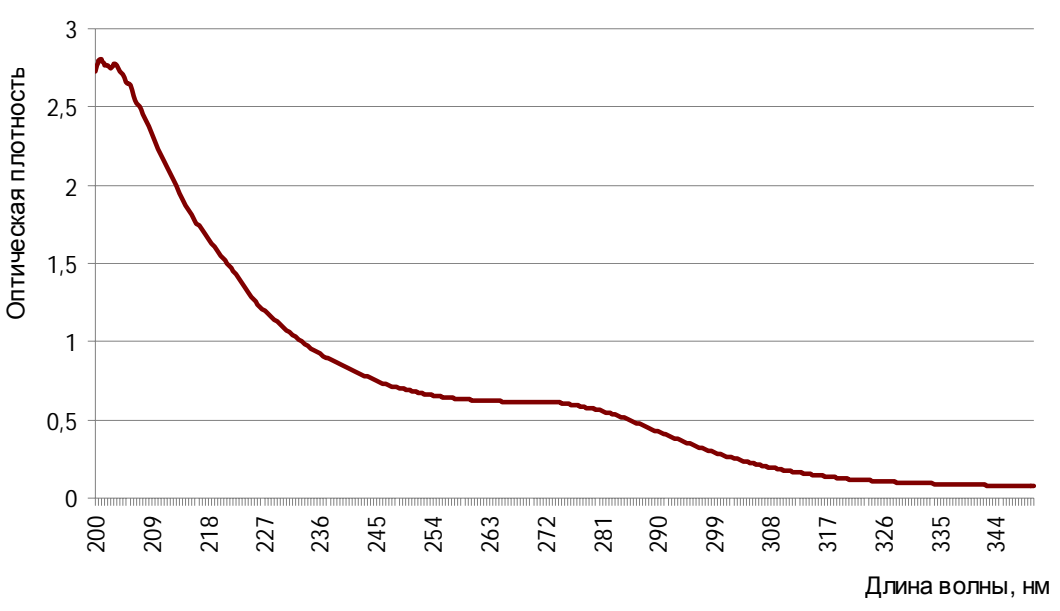

Рис. 1. УФ-спектр этанольного экстракта E. viminalis 
Рис. 2. УФ-спектр гексанового экстракта E. viminalis

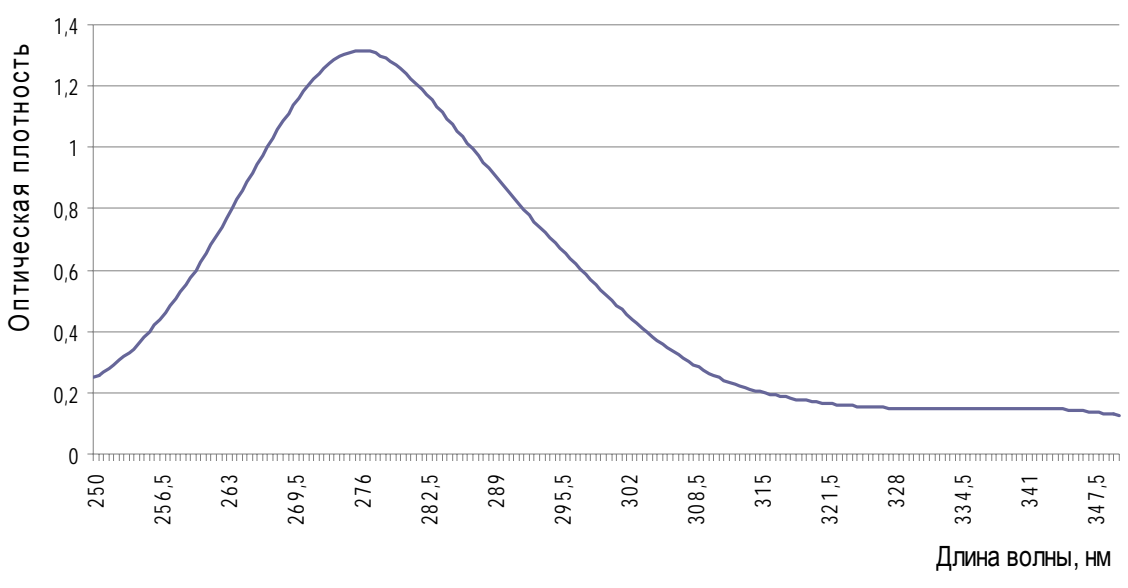

УФ-спектры гексанового и спиртового растворов (без хлорида алюминия) оказались одинаковыми как по характеру кривой, так и по показателю поглощения в точке максимума. Это позволило нам использовать удельный показатель поглощения эвкалимина в спирте для нашей методики.

На дальнейших этапах разработки методики были определены условия исчерпывающей экстракции терпеноидных фенолальдегидов по соотношению сырья и экстрагента и продолжительности нагревания (табл. 1).

Полученные результаты показали, что условиями исчерпывающей экстракции фенолальдегидов из листьев эвкалипта прутовидного является часовая экстракция кипящим гексаном при соотношении сырья и растворителя $1: 200$.

Все вышеизложенное позволило нам предложить следующую методику количественного определения.

Методика количественного определения суммы терпеноидных фенолальдегидов в листьях эвкалипта прутовидного

Аналитическую пробу сырья измельчают до размера 1 мм. Около 1 г сырья (точная навеска) помещают в колбу со шлифом вместимостью 500 мл, прибавляют 200 мл гексана. Колбу присоединяют к обратному холодильнику и нагревают на водяной бане при умеренном кипении гексана в течение 60 мин. Затем колбу охлаждают и фильтруют через бумажный фильтр в мерную колбу вместимостью 200 мл, доводя объем раствора до метки гексаном.

1 мл полученного извлечения переносят в мерную колбу вместимостью 50 мл и доводят объем раствора до метки гексаном. Измерение оптической плотности раствора проводят при длине волны 278 нм, используя в качестве раствора сравнения гексан. Содержание суммы терпеноидных фенолальдегидов в пересчете на эвкалимин и абсолютно сухое сырье в процентах $(\mathrm{X})$ вычисляют по формуле

$$
X=\frac{D \cdot 200 \cdot 50 \cdot 100}{720 \cdot m \cdot 1 \cdot(100-W)},
$$

где D - оптическая плотность испытуемого раствора; 720 - удельный показатель поглощения ГСО эвкалимина; $\mathrm{m}$ - масса сырья в граммах; W - потеря в массе при высушивании, \%.

Для определения метрологических характеристик разработанной методики провели 10 параллельных определений (табл. 2).

Таблица 1. Зависимость выхода фенолальдегидов листьев эвкалипта прутовидного в гексан от параметров экстракции

\begin{tabular}{c|c|c}
\hline $\begin{array}{c}\text { Соотношение сырье (г) } \\
\text { - экстрагент (мл) }\end{array}$ & Время экстракции, мин & $\begin{array}{c}\text { Содержание суммы фенолальдегидов } \\
\text { в пересчете на эвкалимин, \% }\end{array}$ \\
\hline $1: 100$ & 30 & $3,99 \pm 0,03$ \\
$1: 100$ & 60 & $4,98 \pm 0,05$ \\
$1: 100$ & 90 & $5,25 \pm 0,12$ \\
$1: 200$ & 30 & $4,07 \pm 0,09$ \\
$1: 200$ & 60 & $5,58 \pm 0,13$ \\
$1: 200$ & 90 & $5,57 \pm 0,03$ \\
\hline
\end{tabular}


Таблица 2. Метрологические характеристики метода определения фенолальдегидов в листьях эвкалипта прутовидного

\begin{tabular}{c|c|c|c|c|c|c|cc}
\hline $\mathrm{f}$ & $\bar{X}$ & $\mathrm{~S}^{2}$ & $\mathrm{~S}$ & $\mathrm{P}$ & $\mathrm{t}(0,95 ; 9)$ & $\Delta \mathrm{x}$ & $\varepsilon, \%$ \\
\hline 9 & 5,58 & 0,0354 & 0,1881 & 0,95 & 2,26 & 0,13 & $\pm 2,41$ \\
\hline
\end{tabular}

Полученные результаты свидетельствуют об удовлетворительной воспроизводимости методики, ошибка единичного определения не превышает $\pm 2,41 \%$.

Для установления корреляции между содержанием фенолальдегидов, определенных разработанным нами способом, и уровнем антимикробной активности были проведены микробиологические испытания методом двукратных серийных разведений на МПБ $(\mathrm{pH} 7,0)$ и последующим пересевом методом репликаций на чашки Петри с МПА с тест-микробом Staphylococcus aureus ATCC 6538-Р. Для этого гексан из полученных извлечений отгонялся досуха под вакуумом, остаток растворялся в 50 мл 95\% этанола. Полученный раствор подвергался микробиологическим испытаниям (табл. 3).

Испытанный раствор показал высокий уровень антимикробной активности, что подтверждает избирательную экстракцию действующих веществ эвкалипта прутовидного - терпеноидных фенолальдегидов гексаном.

Таблица 3. Антимикробная активность извлечения из листьев эвкалипта прутовидного (на культуре Staphylococcus aureus ATTC 6538-P)

\begin{tabular}{l|c|c|c}
\hline \multicolumn{1}{c|}{ Извлечение } & $\begin{array}{c}\text { Концентрация терпеноид- } \\
\text { ных фенолальдегидов } \\
\text { в извлечении, \% }\end{array}$ & $\begin{array}{c}\text { Максимальное разбавле- } \\
\text { ние извлечения, инактиви- } \\
\text { рующее размножение ста- } \\
\text { филококков }\end{array}$ & $\begin{array}{c}\text { Минимальная подавляю- } \\
\text { щая концентрация терпе- } \\
\text { ноидных фенолальдегидов, } \\
\text { мкг/мл }\end{array}$ \\
\hline $\begin{array}{l}\text { Спиртовой экстракт }(1: 50), \\
\text { полученный после удаления } \\
\text { гексана }\end{array}$ & $0,11 \pm 0,02$ & $1: 256$ & 4,4 \\
\hline
\end{tabular}

\section{Выводы}

1. Разработанный метод количественного определения суммы фенолальдегидов в листьях эвкалипта прутовидного отличается хорошей воспроизводимостью, ошибка не превышает $\pm 2,41 \%$.

2. Высокая антибактериальная активность гексанового экстракта из листьев эвкалипта прутовидного подтверждает избирательную экстрагируемость фенолальдегидов выбранным растворителем.

\section{Сиисок литературы}

1. Государственная фармакопея СССР: Вып. 2. Общие методы анализа. Лекарственное растительное сырье / МЗ СССР. 11-е изд., доп. М., 1989. 400 с.

2. ФСП 42-8000-06. Эвкалипта прутовидного листья / ОАО «Красногорсклексредства». Введ. 16.10.06. М., 2006. $14 \mathrm{c}$.

3. ФСП 42-0039337502 Эвкалипта прутовидного листья. / ОАО «Фармацевтическая фабрика СанктПетербурга». Введ. 30.06.03 СПб., 2003. 14 с.

4. ФСП 42-2007-08. Эвкалипта прутовидного листья / ООО ПКФ «Фитофарм». Введ. 12.05.08. М., 2008. 10 с.

5. С 42-1348-91. Раствор хлорофиллипта спиртовый 1\% / Фармакопейный государственный комитет. Введ. 10.10.91. M., 1991. 4 c.

6. Eschler B.M., Pass D.M., Willis R., Foley W.J. Distribution of foliar formylated phloroglucinol derivatives amongst Eucalyptus species // Biochemical Systematics and Ecology. 2000. Vol. 28. Pp. 813-824.

7. Тюкавкина Н.А., Зурабян С.Э., Белобородов В.Л., Лузин А.П. Органическая химия : учебник для вузов. Кн. 2: Специальный курс / под ред. Н.А.Тюкавкиной. М., 2008. 592 с.

8. Савина А.А., Захаров В.Ф., Цыбулько Н.С. Строение нового фенолальдегида из листьев Eucalyptus viminalis // Химия природных соединений. 1991. №6. С. 789-795. 
Khaziev R.Sh. , Vasilyeva M.V., Makarova A.S., Musina L.T. QUANTITATIVE DETERMINATION OF FORMYLATED PHLOROGLUCINOL COMPOUNDS IN THE LEAVES OF EUCALYPTUS VIMINALIS

Kazan State Medical University, ul. Butlerova, 49, Kazan, 420012 (Russia),e-mail: xaziev@inbox.ru

The way of determination of spectrophotometric method of formylated phloroglucinol compounds in the leaves of $E u$ calyptus viminalis was developed. The relative error of determination doesn't exceed $2,4 \%$. The relation between the level of formylated phloroglucinol compounds determined by the developed method and antibacterial activity of extracts containing them is shown.

Keywords: Eucalyptus viminalis, formylated phloroglucinol compounds, standardization, antibacterial activity.

\section{References}

1. Gosudarstvennaia farmakopeia SSSR: Vyp. 2. Obshchie metody analiza. Lekarstvennoe rastitel'noe syr'e. 11-e izd. [State Pharmacopoeia of the USSR, Vol. 2. Common methods of analysis. Herbal drugs. 11th ed.]. Moscow, 1989, 400 p. (in Russ.).

2. FSP 42-8000-06. Evkalipta prutovidnogo list'ia. OAO «Krasnogorskleksredstva». [Pharmacopoeia article Enterprise 42-8000-06. Eucalyptus leaves. Public limited company «Krasnogorskleksredstva»]. Moscow, 2006, 14 p. (in Russ.).

3. FSP 42-0039337502 Evkalipta prutovidnogo list'ia. OAO «Farmatsevticheskaia fabrika Sankt-Peterburga». [Pharmacopoeia article Enterprise 42-0039337502. Eucalyptus leaves. Public limited company «Farmatsevticheskaia fabrika Sankt-Peterburga»]. St. Petersburg, 2003. 14 p. (in Russ.).

4. FSP 42-2007-08. Evkalipta prutovidnogo list'ia. OOO PKF «Fitofarm». [Pharmacopoeia article Enterprise 42-200708. Eucalyptus leaves. Ltd «Fitofarm»]. Moscow, 2008, 10 p. (in Russ.).

5. FS 42-1348-91. Rastvor khlorofillipta spirtovyi 1\%. Farmakopeinyi gosudarstvennyi komitet. [Pharmacopoeia article 42-1348-91. Hlorofillipta alcohol solution of 1\%. State Pharmacopoeia Committee.]. Moscow, 1991, 4 p. (in Russ.).

6. Eschler B.M., Pass D.M., Willis R., Foley W.J. Biochemical Systematics and Ecology, 2000, vol. 28, pp. 813-824.

7. Tiukavkina N.A., Zurabian S.E., Beloborodov V.L., Luzin A.P. Organicheskaia khimiia: uchebn. dlia vuzov. [Organic chemistry: a textbook for high schools.]. Moscow, 2008, part. 2, 592 p. (in Russ.).

8. Savina A.A., Zakharov V.F., Tsybul'ko N.S. Khimiia prirodnykh soedinenii, 1991, no. 6, pp. 789-795. (in Russ.).

Received July 23, 2013

Revised January 15, 2013

\footnotetext{
* Corresponding author.
} 
